\title{
AERIAL LIDAR TECHNOLOGY IN SUPPORT TO AVALANCHES PREVENTION AND RISK MITIGATION: AN OPERATIVE APPLICATION AT "COLLE DELLA MADDALENA" (ITALY)
}

\author{
P. Boccardo ${ }^{1}$, V. Fissore ${ }^{2, *}$, S. Morreale ${ }^{2}$, E. Ilardi ${ }^{2}$, M. Baldo ${ }^{3}$ \\ ${ }^{1}$ DIST - Interuniversity Department of Regional and Urban Studies and Planning, Politecnico of Turin, Italy - \\ piero.boccardo@polito.it \\ ${ }^{2}$ ITHACA - Information Technology for Humanitarian Assistance Cooperation and Action, Turin, Italy - \\ vanina.fissore@ithaca.polito.it*, salvatore.morreale@ithaca.polito.it, elisa.ilardi@ithaca.polito.it \\ ${ }^{3}$ CNR - IRPI (Italian National Research Council - Research Institute for Hydrogeological Prevention and Protection), Turin, Italy - \\ marco.baldo@irpi.cnr.it
}

\section{Commission IV}

KEY WORDS: Aerial LiDAR, High-resolution 3D models, Controlled Avalanches, Risk Mitigation, Data Integration, Geomorphological Characterization.

\begin{abstract}
:
Snow avalanches are the result of unstable snow masses that detach from steep slopes as consequence of changes in snowpack structure. Nowadays, remote sensing technologies can improve the knowledge of avalanches phenomenon. This work focuses on the use of high point density aerial LiDAR (Light Detection And Ranging) technology as support to avalanche events prevention and risk mitigation, by presenting an operative application at Colle della Maddalena (Italy), along the road SS n. 21, nearby the French state border. The area is often involved in intense avalanche events that adversely impact on traffic and freight transport. For this reason, regional administrations will activate the Avalanche Artificial Detachment Intervention Plan (PIDAV, 2012) in order to prevent and manage the avalanche risk in the study area, also adopting artificial detachment systems. Main aim of the present work was to generate high resolution information related to geomorphological characterization (i.e. digital elevation models, slope and aspect) of avalanche sites derived from LiDAR data processing, that will help involved authorities in the management of the avalanche control plan. Digital elevation models at $0.5 \mathrm{~m}$ of spatial resolution were generated together with relative tridimensional models. Secondly, a preliminary investigation about capabilities and limits of LiDAR technology was done in the identification of avalanche sites only relying on geomorphological information directly derived by LiDAR data processing. Results showed that position of avalanche sites were correctly identified while no information could be obtained about the extension of the sliding area and identification of detachment areas.
\end{abstract}

\section{INTRODUCTION}

Mountain areas, due to the high geomorphology variability, are typically subjected to natural hazards such as snow avalanches. These are the result of unstable snow masses that detach from steep slopes as consequence of changes in snowpack structure mainly due to modifications of environmental temperature conditions, with a direct influence on water content and cohesion within snow cover (Lato et al., 2012). Snow avalanches can occur in various meteorological situations, within variable terrain and can manifest themselves in many forms. Snow avalanche formation is typically depending on parameters such as snowfall, temperature, wind direction and speed, snowpack conditions, slope orientation, terrain conditions and vegetation presence (Armstrong and Armstrong, 1987; Gubler and Bader, 1989; McClung and Schaerer, 1993).

The impacts of snow avalanches range from delays and financial loss through road and railway closures, destruction of property and infrastructure, to loss of life. Avalanche warnings today are mainly based on meteorological information, field observations of snowpack conditions and historically recorded avalanche events (Lato et al., 2012).

Thus, avalanche research is a risk research, dealing with risk reduction by trying to understand avalanche formation in space and time, relative to meteorological and snowpack triggering factors (McClung, 2002; Schweizer et al., 2003, 2008). Traditionally, field-testing of snow properties, field investigation of avalanche activity and dynamics, and modeling of both, are used to study avalanche formation and risk (Eckerstorfer et al., 2016).
The use of innovative remote sensing technologies enables objective, safe and spatial continuous observations of snow avalanches at different spatial scales (Eckerstorfer et al., 2016), improving the study of avalanche activity and dynamics, and also providing a better knowledge of areas crossed by avalanche events. Specifically, aerial LiDAR (Light Detection And Ranging) technology can provide high resolution information about topography, which is one of the main factor influencing avalanches formation and behavior, through the identification and characterization of more impervious zones such as ridges and watersheds.

In this context, the present work focuses on the use of high point density aerial LiDAR technology as support to risk mitigation and avalanche phenomenon prevention. The study area is located nearby the road SS n. 21 at Colle della Maddalena, an important cross-border communication route between Italy and France. In the winter season, during heavy snowfalls, the stretch of road between the village of Argentera $(\mathrm{CN})$ and the state border is involved in intense avalanche events that adversely impact on local and border traffic and freight transport. For this reason, regional administration would adopt a control activity on priority areas together with artificial detachment methods, with the aim to minimize the risk. In fact, at present, the maintaining of the safety conditions of the road, forces regular closure periods when heavy snowfalls or presence of high level of avalanche risk occur. The road closing periods can be very long, with consequent negative effects on socio-economic activities. The artificial detachment of the snowpack, at a certain time, will considerably reduce the road closing time span and, of course, minimize the risk related to people/infrastructure safety. 
With these premises, main aim of the present work was to present an operative application of the use of high density aerial LiDAR technology in support to avalanche events prevention and risk mitigation, particularly referring to area geomorphological characterization. Secondly, an investigation about capabilities and limits of the LiDAR technology was done in the identification of avalanche sites, only relying on geomorphological information directly derived by LiDAR data processing.

Obtained results are then integrated with historical data deriving from field campaigns carried out in the past winter seasons, and with data contained within the PIDAV (Avalanche Artificial Detachment Intervention Plan, 2012). The already available data and the products obtained by LiDAR data processing are collected, harmonized and organized in GIS environment through the implementation of a dedicated geospatial database, and delivered to involved authorities for appropriate consultation.

\section{MATERIALS AND METHODS}

\subsection{Study area}

The study area is located at Colle della Maddalena (Argentera, CN, Italy) nearby the French state border, and concerns the right orographic mountain slope above the terminal part of the road SS n. 21. This last crosses a valley section morphologically and climatically predisposed to the occurrence of avalanche phenomenon, allowing the access to an important international pass, particularly used for commercial transport in the western Alpine sector. The study mountain slope is South-West oriented and characterized by very complex geomorphology, with slope values up to 89 degrees; elevation ranges from $1690 \mathrm{~m}$ a.s.l. up to $2770 \mathrm{~m}$ a.s.1.. The analyzed area covers an extension of about $7 \mathrm{~km}^{2}$. Due to the extreme environmental conditions, no tree vegetation cover is present for majority of the area. Consequently, by its nature the area is subject to slope instability with the consequent high risk of avalanches formation during the winter and the spring seasons and when heavy and concentrated snowfalls occur. Since the predisposition of the area to avalanche risk, from year 1984 an automatic climatic station positioned in Argentera (1680 $\mathrm{m}$ a.s.1.), recorded nivo-meteorological data, until year 2011. Data analysis during this time span provided the following information:

- 29 snowy days per year (average number);

- $260 \mathrm{~cm}$ of maximum snow depths, reached for the considered time span;

- $\quad 95 \mathrm{~cm}$ of maximum amount of fresh snow fallen in 24 hours;

- $\quad 185 \mathrm{~cm}$ of maximum value of snow variation in three consecutive days (a recent episode of intense snowfall - December 2008 - which generated large avalanches, presented a variation of snow of 121 $\mathrm{cm})$.

\subsection{The Avalanche Artificial Detachment Intervention Plan (PIDAV, 2012)}

In 2012, an Avalanche Artificial Detachment Intervention Plan (PIDAV, 2012) was established by regional authorities for the prevention and management of avalanche risk in the study area. The Plan provides a detailed description of the area with specific focus on avalanche sites, identifying 14 of these last as actually affecting the road SS n. 21 annually or several times a year. Moreover, the Plan describes existing artificial detachment systems and the methodology followed during artificial snowpack detachment. Specifically, artificial snowpack detachment procedures within identified avalanche sites will be activated at a certain threshold of snowpack depth, corresponding to $30 \mathrm{~cm}$, as stated by the numerical avalanche path simulation obtained using Rapid Mass Movement Simulation (RMMS) model (Christen et al., 2010). This will guarantee to generate smaller and controlled snow mass movements and, consequently, to avoid the formation of excessive snow thickness from which greater avalanches could generate.

The threshold of $30 \mathrm{~cm}$ will be observed directly from the road by remote observation on ad hoc snow poles, positioned within the highest parts of the detachment areas of avalanche sites, presenting graduated coloring and thus permitting an easy reading of snowpack depth. When the threshold of 30 $\mathrm{cm}$ is observed, then detachment procedures are activated with simultaneous closure of the road, so as to avoid the danger and risk of larger proportions avalanches formation. Two avalanche detachment systems are used: the Daisy Bell® system, which need to be carried by helicopter up to the top of avalanches sites, in addition to fixed Gazex® exploders. Despite the first type allows a flexible and a case by case basis choice of the areas subjected to the explosion, it efficacy strictly depends on good weather conditions necessary for helicopter flight. Consequently, also fixed Gazex® exploders are installed at specific locations, ensuring controlled avalanches triggering also during snowfalls.

\subsection{Available cartographic data}

In addition to LiDAR data, a series of basic cartographic data contained within the PIDAV were available, and adopted for the performed analysis. Specifically, a geospatial database (.gdb) containing feature classes, was adopted. Contained information are relative to general information about the area (e.g. road network, administrative limits, land cover and hydrology) and to more specific information regarding avalanche sites, such as snowpack detachment areas position, avalanche extension identified by different methods (i.e. photo-interpretation, ground observations, model simulations), snow pole position, Daisy Bell ${ }^{\circledR}$ system and Gazex® exploders positions. All these data were used as reference data and managed in GIS environment for performed analysis.

\subsection{Aerial LiDAR mission}

The aerial LiDAR mission was carried out on the 16th of October 2019, before the beginning of the winter season and before any snowfall event.

The adopted system (Figure 1), property of CNR - IRPI (Italian National Research Council - Research Institute for Idrogeological Prevenction and Protection) and managed by the CNR-GMG (Geohazard Monitoring Group), is based on a Litemapper 6800 system engineered inside an external EASA certified POD (minor/STC approval for AIRBUS EUROCOPTER AS350/355) and composed by the main following hardware:

- $\quad$ LiDAR RIEGL LMS-Q680i full-waveform sensor;

- HASSELBLAD H3D-II 39 Mpixel - 50mm focal lenght medium format aerial camera;

- $\quad$ GPS-INS novatel OEM4 / IMU IGI-IIf 256Khz (calibrated on September 2019). 


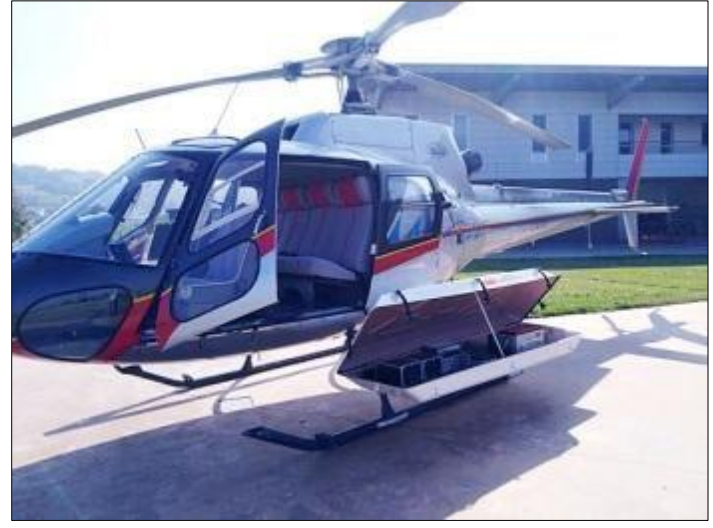

Figure 1. CNR IRPI aerial LiDAR mounted on EUROCOPTER AS350-B2

The system, for boresight calibration solution, performed also a dedicated flight on a calibration pattern represented by 6 cross-strips over a calibration area. Offsets from GNSS antenna and IMU (Inertial Measurement Unit) reference point was solved using a 1 " total station calibrated during year 2018.

Estimated accuracy, evaluated comparing official geodetic benchmarks over the area, shows that altimetric standard deviation over the ETRF 2000 reference ellipsoid is approximately $10 \mathrm{~cm}$ with an average beam footprint (beam divergence) of $12 \mathrm{~cm}$.

The mission, composed by 12 flightstrips $(60 \%$ - 30\% forward and sidelap coverage) (Figure 2), was flown at $60 \mathrm{GS}$ aerial knots (GS - Ground Speed) and on a $300 \mathrm{kHz}$ RPP (Repetition Pulse Rate) over the Multiple-time around zone 1-3, with variable AGL (Above Ground level) from 147 to $922 \mathrm{~m}$. Point density was between 8 and $33 \mathrm{pls} / \mathrm{sq}$ with an average of $21 \mathrm{pls} / \mathrm{sq}$.

Total surveyed area resulted of $7,25 \mathrm{~km}^{2}$.

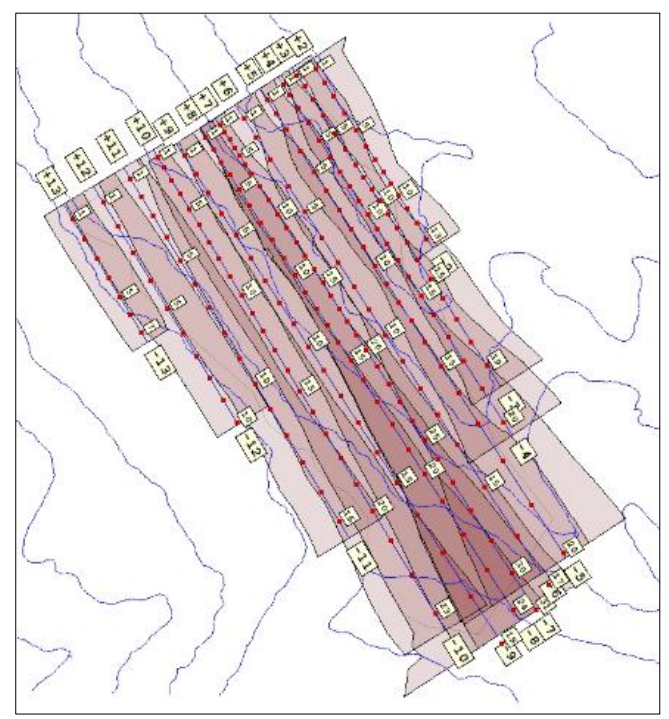

Figure 2. Flightplan geometry, 12 flightstrips presenting $60 \%$ and $30 \%$ of forward and sidelap coverage, respectively.

\subsection{LiDAR data processing and terrain analysis}

Figure 3 reports the flowchart relative to adopted workflow.

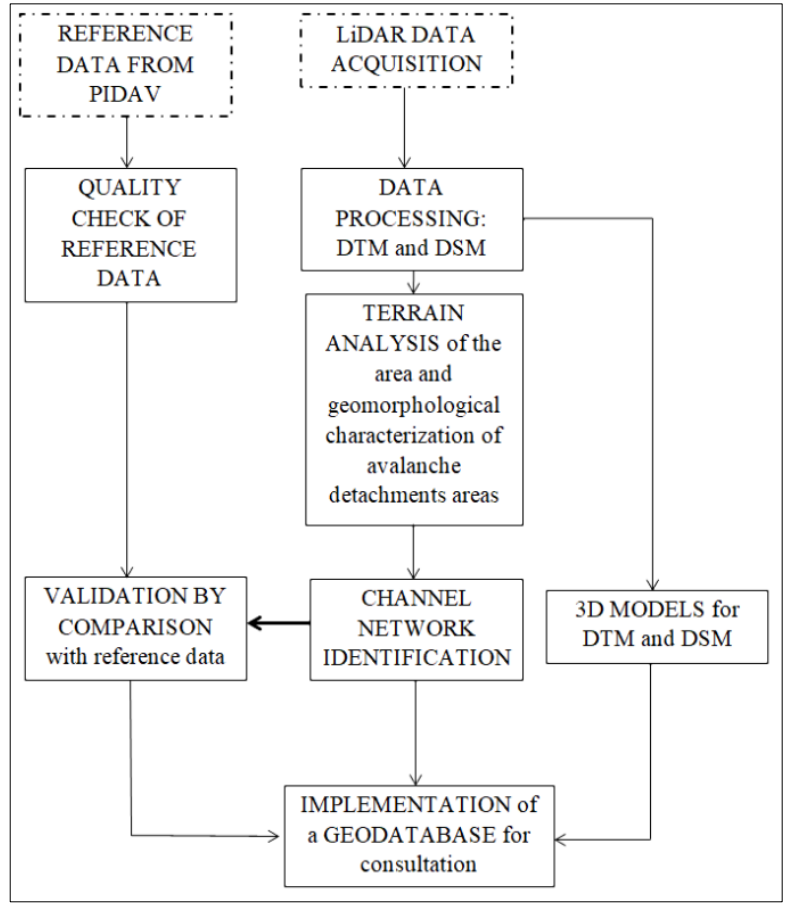

Figure 3. Flowchart of adopted workflow.

Raw LiDAR point cloud was pre-processed using TerraScan application (TerraSolid SW). Below Figure 4 shows the highresolution 3D model of the raw point clouds in RGB color.

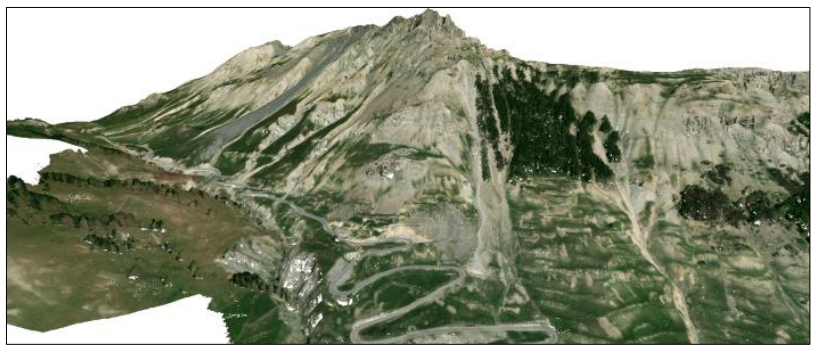

Figure 4. High-resolution 3D model of raw point clouds in RGB color.

With reference to LiDAR point cloud classification and filtration, due to the morphological and vegetation characterization of the surveyed slope, a geometrical LiDAR classification was preferred instead of a full-waveform data processing.

The slope, in fact, mainly presents exposed rocks with no vegetation, with a small isolated spot of bushes and some conifer trees. For this reason, the $80 \%$ of the dataset taken can be considered as ground point cloud, with small areas that needs more classification algorithms.

Specifically, an iteratively triangulated surface model routine was used to detect ground points: this classification type determines how close a point must be to a triangle plane for being accepted as ground point and added to the model.

Because no artifacts (or very few) are present over the area, the main parameter chosen for a maximum artifacts size present was set at $30 \times 30 \mathrm{~m}$.

The following additional iteration parameters were also adopted: Iteration angle (i.e. maximum angle between a point, its projection and the closest triangle vertex) and Iteration distance (distance between two ground candidate points), set, as indicated for mountain areas, to 10 - 
12 degrees and of 0.3 meters, respectively. This distance, very small, is useful to avoid that points belonging to low vegetation like small bushes can be considered as ground points.

Finally, but fundamental, the average terrain angle of the mountain slope, was assumed to be 30 degrees.

The final dataset was cross-checked with a shade surface to detect and remove spikes (using local cross-sections) generated by noise points fluctuating over the DTM (Digital Terrain Model) surface. Obtained DTM has a pixel size of $0.5 \mathrm{~m}$.

Subsequently, also a $0.5 \mathrm{~m}$ pixel size DSM (Digital Surface Model) was generated with Global Mapper software (v 21.1), by using the dedicated LiDAR Module.

In order to better characterize the area from a geomorphological point of view, some preliminary terrain analysis were performed with SAGA GIS (v 7.4). Aspect, slope, convexity and wind exposition information were obtained for the study area and some descriptive statistics calculated for the avalanche detachment areas contained within available reference data.

Wind Exposition Index was adopted to derive wind exposition information; computation is fully implemented in the free and open-source geographical information system SAGA GIS (Gerlitz, L., Conrad, and O., Böhner, J., 2015) and relative equation is reported in Eq. 1. This index is based on the Wind Effect Index which considers windward and leeward areas (Boehner, J. and Antonic, O., 2009).

$$
H=H_{L} * H_{W}
$$

where, $H_{L}$ is the leeward index and $H_{W}$ is the windward index.

As regard to the convexity analysis, profile curvature information was derived using Zevenbergen \& Thorne (1987) method, fully implemented in SAGA GIS.

Moreover, a "flow accumulation" analysis (Top-down, Deterministic 8 method) (O'Callaghan J.F. and Mark D.M., 1984) was computed for the area to identify watersheds position (i.e. most depressed points of the water basin where flowing rainwater flows) in order to show if, with the only use of LiDAR derived data, identification of position of known avalanche sites was achievable. Validation of obtained results was performed through comparison by overlapping with available reference cartographic data.

Finally, the 3D View module of Global Mapper permitted to obtain high-resolution tridimensional models for DTM, DSM, slope and aspect.

\section{RESULTS AND DISCUSSION}

\subsection{Data analysis}

Following Figures 5 and 6 show obtained Digital Terrain Model and Digital Surface Model with focus on a specific area where tree cover is present, in order to better appreciate the different information supplied by the two data.

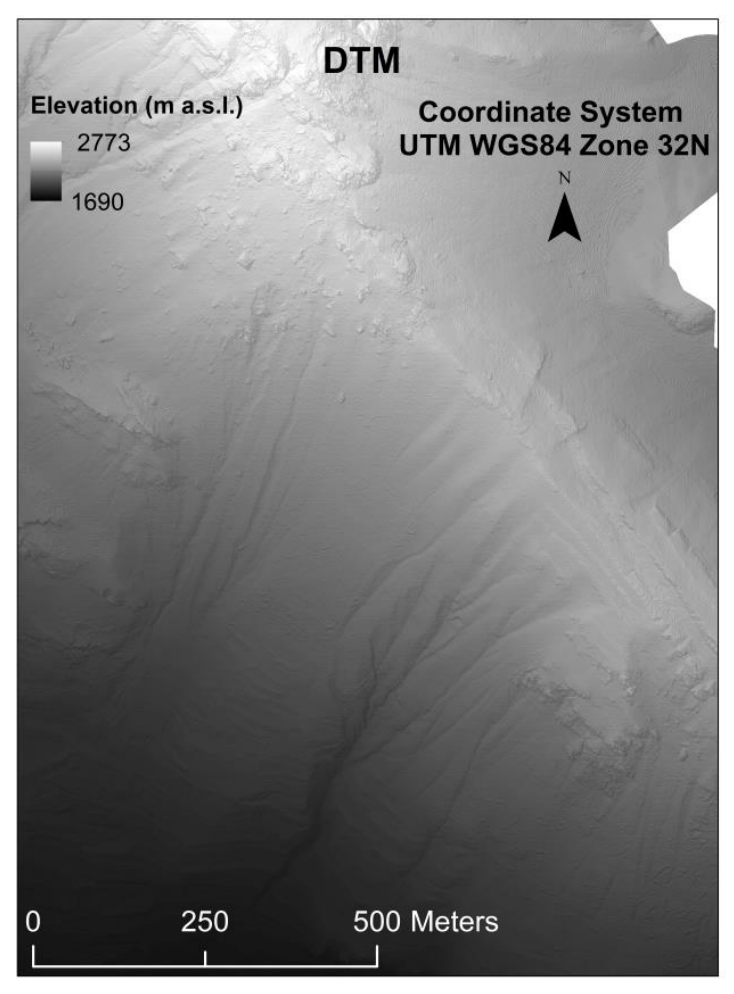

Figure 5. Particular of generated DTM

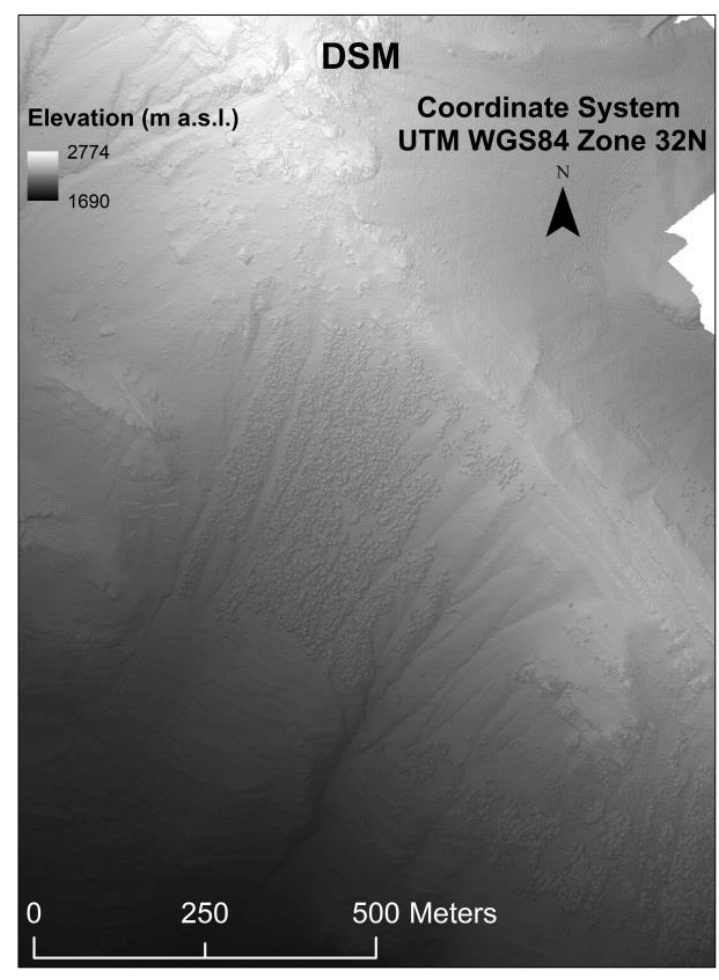

Figure 6. Particular of generated DSM, tree cover is visible on the right mountain slope.

Obtained DTM was subsequently used to obtain some geomorphological information by performing terrain analysis of slope, aspect, wind exposure and convexity. Digital maps were generated and descriptive statistics of the avalanche detachment areas (DA) were computed. Table 1 reports mean values of computed parameters. 


\begin{tabular}{|c|c|c|c|c|c|}
\hline DA & $\begin{array}{c}\text { ELEVATION } \\
\text { (m a.s.1.) }\end{array}$ & $\begin{array}{c}\text { SLOPE } \\
\text { (deg.) }\end{array}$ & $\begin{array}{c}\text { ASPECT } \\
\text { (deg.) }\end{array}$ & $\begin{array}{c}\text { WIND } \\
\text { EXPOSITION } \\
\text { (NDEX }\end{array}$ & $\begin{array}{c}\text { PROFILE } \\
\text { CURVATURE }\end{array}$ \\
\hline 1 & 2.077 & 33.68 & 227.79 & 1.15 & 0.000332 \\
\hline 2 & 2.665 & 36.23 & 230.13 & 1.2 & 0.000265 \\
\hline 3 & 2.392 & 39.98 & 184.09 & 1.12 & 0.001088 \\
\hline 4 & 2.685 & 36.93 & 170.06 & 1.11 & 0.000354 \\
\hline 5 & 2.625 & 37.27 & 256.51 & 1.21 & 0.000241 \\
\hline 6 & 2.276 & 37.87 & 213.16 & 1.16 & -0.000158 \\
\hline 7 & 2.545 & 43.24 & 213.08 & 1.17 & 0.001088 \\
\hline 8 & 2.546 & 40.54 & 225.74 & 1.16 & 0.000393 \\
\hline 9 & 2.445 & 43.45 & 238.23 & 1.18 & 0.000236 \\
\hline 10 & 2.401 & 45.98 & 226.58 & 1.17 & 0.000484 \\
\hline 11 & 2.298 & 39.81 & 196.94 & 1.13 & -0.000192 \\
\hline 12 & 2.297 & 40.69 & 197.41 & 1.12 & 0.000363 \\
\hline 13 & 2.156 & 41.77 & 224.61 & 1.14 & 0.000468 \\
\hline 14 & 2.191 & 38.76 & 229.59 & 1.15 & 0.000123 \\
\hline 15 & 2.534 & 39.98 & 221.61 & 1.16 & 0.000666 \\
\hline 16 & 2.348 & 39.11 & 241.52 & 1.18 & 0.000100 \\
\hline 17 & 2.647 & 35.82 & 240.82 & 1.2 & 0.000135 \\
\hline 18 & 2.493 & 43.94 & 211.17 & 1.16 & 0.000678 \\
\hline & & & & & \\
\hline
\end{tabular}

Table 1. Statistics of geomorphological parameters of avalanche detachment areas (DA). Mean values are reported.

Table 1 shows that all detachment areas are within the range of $30^{\circ}$ and $45^{\circ}$ of slope and mainly South-West oriented.

As regard to the convexity analysis, values above zero describes convex profile curvature, values below zero concave profiles. Reported statistics shows that majority of detachment areas have positive values, thus convex profiles. The Wind Exposition Index is a dimensionless index. It was computed for all directions using an angular step of $15^{\circ}$. Values below 1 indicate wind shadowed areas whereas values above 1 indicate areas exposed to wind. Statistics shows that all detachment areas presents positive values, i.e. are exposed to wind, where snow accumulation due to wind action is more likely.

As regard to Flow accumulation analysis, surface depressions within the input DTM where first identified and then filled for the whole area, by using the Fill Sinks module (Wang \& Liu, 2006). Subsequently, the accumulated flow was obtained by using the Flow accumulation (Top-down) module. Results show that cell values greater than the threshold of 18000 well characterized areas crossed by avalanche events, as demonstrated by evaluation of reference cartographic data. Consequently, only flows above this value, set as initiation threshold for the channel network generation (i.e. watersheds) of the study area, were considered for the relative analysis (Figure 7).

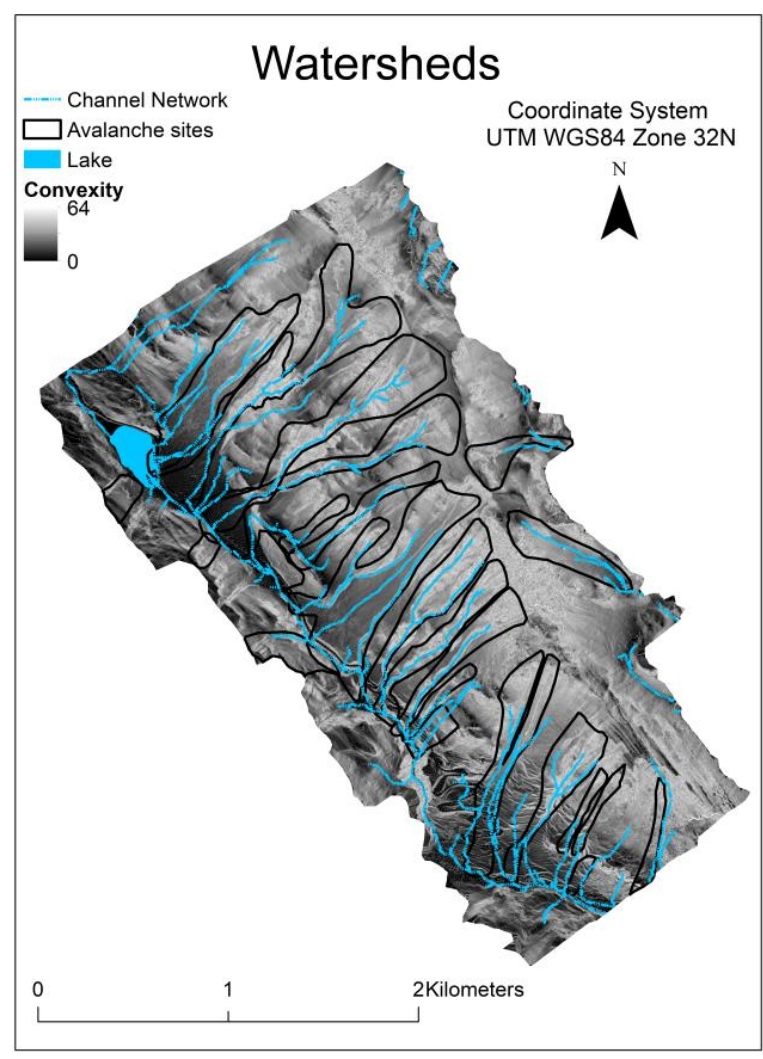

Figure 7. Channel network (i.e. watersheds) of the area (light-blue lines) generated from LiDAR derived data, which mainly corresponds to avalanche sites derived from ground observation (black polygons).

The analysis identified all the areas crossed by avalanche events reported in the PIDAV plan, providing information about the position of the avalanche sites. Instead, no information is achievable about the extension of the potential sliding area, since this last also depends on snow parameters such as snow depth, snowpack structure, etc..

Moreover, in order to understand if LiDAR derived data by themselves were sufficient to identify "potential" avalanche detachment areas only relying on geomorphological parameters, a graticule grid of $100 \times 100$ m covering the whole study area was generated. Statistics about mean values of slope, aspect, convexity and wind exposure were computed within the graticule cells with the aim of identifying potential detachment areas. Results, as shown in Figure 8, show that almost all detachment areas of the reference data where identified, but also that a great overestimation is present. Again, metric parameters about snowpack structure results to be necessary. 


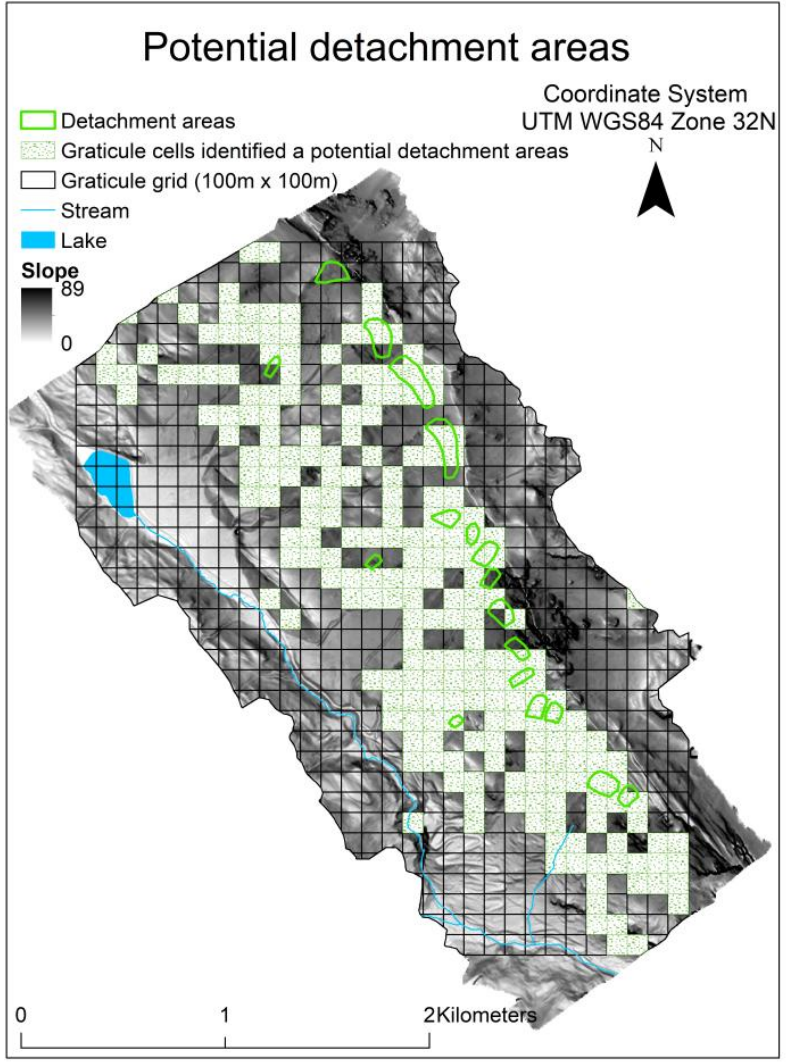

Figure 8. Graticule cells detected as "potential" detachment areas and greatly overestimated. Green polygon are reference detachment areas.

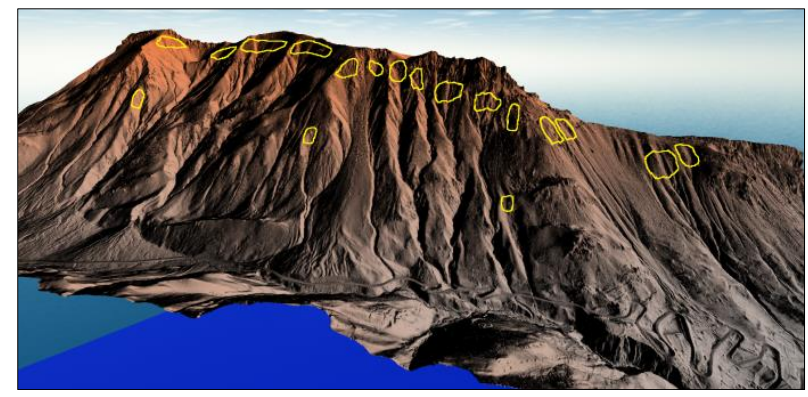

Figure 9. High-resolution tridimensional DTM of the study area obtained with Global Mapper SW, 3D view module. Yellow circles are reference snow avalanches detachment areas.

\section{CONCLUSIONS}

This work was mainly aimed at presenting an operative application of the use of high density aerial LiDAR technology in support to avalanche events prevention and risk mitigation. The study area is located at Colle della Maddalena (Argentera, CN, Italy), nearby the French state border, and concerns the terminal part of the road SS n. 21, an important and international pass particularly used for commercial transport in the western Alpine sector. The SS n. 21 crosses a valley section morphologically and climatically predisposed to the occurrence of avalanche phenomenon. The processing of LiDAR data permitted to obtain high resolution derived data, in particular DTM and DSM of $0.5 \mathrm{~m}$ spatial resolution were generated. In order to better characterize the study area from a geomorphological point of view, slope, aspect, convexity and wind exposure data were obtained. The detailed morphological characterization of the area, together with the high-resolution tridimensional digital terrain models, will help regional and local authorities in the definition and management of the avalanche control plan, by providing information related to elevation, steepness and exposure of avalanche sites.

Further, a second kind analysis was performed to understand capabilities, potentialities and limits of the LiDAR technology in the identifications of the "potential" avalanche detachment areas only relied on geomorphological information directly derived by LiDAR data processing. Obtained results showed that position of the avalanche sites were correctly identified, while no information could be obtained about the extension of the sliding area, since this last also depends on snow parameters such as snow depth, snowpack structure, etc.. The same can be said for detachment area identification, not possible only considering geomorphological parameters. Information about snowpack structure results to be necessary.

Potentialities of the adopted approach can be identified in the following:

- A further aerial LiDAR acquisition during the winter season and with snow presence on the ground would allow to know snowpack elevation value. Knowledge of such value would permit to derive snow depth information at detachment areas and, consequently, better identify, together with already computed geomorphological parameters, "potential" detachment areas.

- Aerial LiDAR acquisitions before and after the avalanche events would permit to apply a change detection analysis, allowing the measurement of the extension of detachment and sliding -areas.

\section{ACKNOWLEDGEMENTS}

Authors would like to thank the Piedmont Region Infrastructure and Mobility Management Direction and the Province of Cuneo.

\section{REFERENCES}

Armstrong, R. L., Armstrong, B. R., 1987. Snow and avalanche climates of the western United States: A comparison of maritime, intermountain and continental conditions, Avalanche Formation, Movement and Effects, Proceedings of the Davos Symposium, IAHS Publ. No. 162, 1987.

Boehner, J., Antonic, O., 2009. Land-surface parameters specific to topo-climatology. in: Hengl, T., Reuter, H. (Eds.): 'Geomorphometry - Concepts, Software, Applications'. Developments in Soil Science, Volume 33, 195-226, Elsevier.

Christen M., Kowalski J. and \& Bartelt P., 2010. RAMMS Numerical simulation of dense snow avalanches in threedimensional terrain. Cold Regions Science and Technology. 63. 1-14. 10.1016/j.coldregions.2010.04.005.

Eckerstorfer M., Bühler I., Frauenfelder R., Malnes E., 2016. Remote sensing of snow avalanches: recent advances, potentials, and limitations. Cold region science and technology, 121, 126-140, https://doi.org/10.1016/j.coldregions.2015.11.001.

Gerlitz, L., Conrad, O., Böhner, J., 2015. Large scale atmospheric forcing and topographic modification of precipitation rates over High Asia - a neural network based 
approach. Earth System Dynamics, 6, 1-21. doi:10.5194/esd6-1-2015.

Gubler, H., Bader, H. P., 1989. A model of initial failure in slab avalanche release, Annals of Glaciology, 13, 90-95.

M. J. Lato, R. Frauenfelder, Y. Bühler, 2012. Automated detection of snow avalanche deposits: segmentation and classification of optical remote sensing imagery. Nat. Hazards Earth Syst. Sci., 12, 2893-2906, www.nat-hazardsearth-syst-sci.net/12/2893/2012/ doi:10.5194/nhess-12-28932012.

McClung, D. and Schaerer, P., 1993. The Avalanche Handbook, The Mountaineers, Seattle Washington, USA.

McClung, D.M., 2002. The Elements of Applied Avalanche Forecasting, Part I: The Human Issues. Natural Hazards 26, 111-129.

https://doi.org/10.1023/A:1015665432221.

O'Callaghan J.F. and Mark D.M., 1984. The extraction of drainage networks from digital elevation data. Computer Vision, Graphics and Image Processing, 28:323-344.http://dx.doi.org/10.1016/S0734-189X(84)80011$0)$.

Piano di Intervento di Distacco Artificiale di Valanghe PIDAV (Avalanche Artificial Detachment Intervention Plan), ALCOTRA Program 2007-2013, "RISKNAT Project". 2012. Infrastructure and Mobility Management Direction, Piedmont Region.

Schweizer J., Jamieson J. B., Schneebeli M., 2003. Snow avalanche formation. Review of Geophysics, 41(4), 1-25, https://doi.org/10.1029/2002RG000123.

Schweizer J., Kronholmb K., Jamiesonc J. B., Birkelandd k. W., 2008. Review of spatial variability of snowpack properties and its importance for avalanche formation. Cold Regions Science and Technology. 51(2-3), 253-272. https://doi.org/10.1016/j.coldregions.2007.04.009.

Wang, L., Liu H., 2006. An efficient method for identifying and filling surface depressions in digital elevation models for hydrologic analysis and modelling. International Journal of Geographical Information Science, 20(2), 193-213.

Zevenbergen, L.W., Thorne, C.R., 1987. Quantitative analysis of land surface topography. Earth Surface Processes and Landforms, 12, 47-56. 